\title{
Hepatic Reduction of Carbamoyl-PROXYL in Ferric Nitrilotriacetate Induced Iron Overloaded Mice: An in Vivo ESR Study
}

\author{
Noppawan Phumala Morales, ${ }^{* a}$ Yumiko Yamaguchi, ${ }^{b}$ Kimiyo Murakami, ${ }^{b}$ Nuttavut Kosem, ${ }^{c}$ and \\ Hideo Utsumi ${ }^{b, c}$ \\ ${ }^{a}$ Department of Pharmacology, Faculty of Science, Mahidol University; Rama 6 Rd, Rajatevee, Bangkok 10400, \\ Thailand: ${ }^{b}$ Department of Bio-Function Science, Faculty of Pharmaceutical Science, Kyushu University; and ${ }^{c}$ In- \\ novation Center for Medical Redox Navigation, Kyushu University; 3-1-1 Maidashi, Higashi-ku, Fukuoka 812-8582, \\ Japan. Received November 24, 2011; accepted April 13, 2012
}

\begin{abstract}
Reduction of a nitroxyl radical, carbamoyl-PROXYL in association of free radical production and hepatic glutathione (GSH) was investigated in iron overloaded mice using an in vivo L-band electron spin resonance (ESR) spectrometer. Significant increases in hepatic iron, lipid peroxidation and decrease in hepatic GSH were observed in mice intraperitoneally (i.p.) administrated with ferric nitrilotriacetate (Fe(III)NTA, a total $45 \mu \mathrm{mol} / \mathrm{mouse}$ over a period of 3 weeks). Free radical production in iron overloaded mice was evidenced by significantly enhanced rate constant of ESR signal decay of carbamoyl-PROXYL, which was slightly reduced by treatment with iron chelator, deferoxamine. Moreover, the rate constant of ESR signal decay was negatively correlated with hepatic GSH level $(r=-0.586, p<0.001)$. On the other hand, hepatic GSH-depletion $(>\mathbf{8 0} \%)$ in mice through daily i.p. injection and drinking water supplementation of L-buthionine- $[S, R]$-sulfoximine (BSO) significantly retarded ESR signal decay, while there were no changes in serum aspartate aminotransferase and liver thiobarbituric acid-reactive substances levels. In conclusion, GSH plays two distinguish roles on ESR signal decay of carbamoyl-PROXYL, as an antioxidant and as a reducing agent, dependently on its concentration. Therefore, it should be taken into account in the interpretation of free radical production in each specific experimental setting.
\end{abstract}

Key words glutathione; ferric nitrilotriacetate; L-band ESR; nitroxyl radical

Chronic iron overload is one of the most clinically important manifestations in hemochromatosis and thalassemia. In the latter case, long term iron overload, resulting from regular blood transfusion or increased gut iron absorption, leads to malfunction of organs, which have high levels of iron accumulation. ${ }^{1)}$ The major causes of death in hereditary hemochromatosis are due to hepatic failure with cirrhosis or hepatocelluar carcinoma, as the consequences of excess iron in the liver. ${ }^{2)}$ Free radical reactions have been proposed as a key step for iron toxicity. However, direct evidence of free radical production in vivo has been rarely demonstrated.

In vivo electron spin resonance (ESR) spectroscopy using nitroxyl spin probes is a non-invasive and a real time technique that is applicable for studies of free radical production in living animals. ${ }^{3)}$ The nitroxyl spin probes react with hydroxyl radicals, superoxide anion ${ }^{4)}$ and various endogenous reducing agents, such as ascorbic acid, glutathione (GSH), reduced form of nicotinamide adenine dinucleotide (NADH) and nicotinamide adenine dinucleotide phosphate (NADPH $),{ }^{5-7)}$ resulting in the loss of ESR signal. Thus, the rate of ESR signal decay of nitroxyl spin probes have been used to monitor free radical production and redox status in various animal models, including tumor inoculated in mouse footpads, ${ }^{8)}$ indomethacin-induced gastric ulcers, ${ }^{9}$ rheumatoid arthritis, ${ }^{10)}$ hypertension, ${ }^{11}$ cerebral ischemia-reperfusion, ${ }^{12}$ lung injury caused by diesel exhaust particles, ${ }^{13)}$ and radiationinduced oxidative injury. ${ }^{14)}$

Phumala et al. ${ }^{15)}$ have demonstrated in an acute iron overload murine model that free radical production is dependent on the availability of "chelatable iron" present transiently following a single injection of ferric citrate $(0.2 \mu \mathrm{mol} / \mathrm{g}$ body weight). Moreover, the efficacy of an iron chelator, deferoxamine, to inhibit the enhancement of ESR signal decay is related also to the level of "chelatable iron" in the blood compartment. However, in chronic iron overload, the distribution of cellular and tissue iron is diverse, and it could be expected that the variety of types of endogenous antioxidants may influence iron-induced free radical production and consequently the rate of ESR signal decay.

Ferric nitrilotriacetate (Fe(III)-NTA) is a well known potent carcinogen in liver and kidney. Repeated intraperitoneal (i.p.) administrations of $\mathrm{Fe}(\mathrm{III})-\mathrm{NTA}$ to male mice and rats produce acute and sub-acute proximal tubular necrosis. ${ }^{16,17)}$ In addition, Fe(III)-NTA has been demonstrated to be a potent hepatic tumor promoter. Hepatic ornithine decarboxylase (ODC) activity and hepatic DNA synthesis, markers of the promotion state of hepatic carcinogenesis, are enhanced in a dose-dependent manner in rats treated with $\mathrm{Fe}(\mathrm{III})-\mathrm{NTA}{ }^{18)}$ Injection of $\mathrm{Fe}(\mathrm{III})$-NTA originally was introduced to produce an experimental model of hemochromatosis. ${ }^{19)}$ Fe(III)-NTA passes through mesothelium and is absorbed though the portal vein into the liver and systemic blood flow. Heavy iron deposits were found in liver parenchymal cells and some in Kupffer cells. Elevated lipid peroxidation, hydrogen peroxide generation and DNA-protein cross linked adducts as well as depletion of glutathione and glutathione-dependent antioxidant enzymes in rat liver were evidences of oxidative stress induced by Fe(III)-NTA. Pretreatment with vitamin E was able to reverse these changes. ${ }^{20)}$

In this study, chronic iron overload mice were produced by repeated i.p. injection of $\mathrm{Fe}$ (III)-NTA, and free radical production in the hepatic region was followed in vivo by monitoring ESR signal decay of carbamoyl-PROXYL. We hypothesized that, in addition to free radicals, ESR signal decay of the nitroxyl spin probe may also be influenced by alterations in redox status following long term iron intoxication. Since GSH is 
an abundant antioxidant in tissue and is also a reducing agent of nitroxyl probe, the involvement of GSH in the protection of oxidative stress induced by Fe(III)-NTA was also evaluated.

\section{MATERIALS AND METHODS}

Animal and Iron Overloading Male ddy mice (4 weeks of age, 20-24g) were purchased from Seac Yoshitomi Co. (Fukuoka, Japan). Animals were acclimatized for 1 week before experiments. Diet (MF, Oriental Yest Co., Tokyo, Japan) and water were provided ad libitum.

Mice were i.p. injected with Fe(III)-NTA for 3 weeks as follow Awai et al. ${ }^{19)}$ Ferric nitrate $(100 \mathrm{~mm})$ and nitrilotriacetic acid disodium salt (NTA, Aldrich Chem. Co., Milwaukee, WI, U.S.A.) (200 mM) were freshly prepared in deionized water and mixed at a ratio of $1: 1(\mathrm{v} / \mathrm{v})$. The $\mathrm{pH}$ was adjusted with solid sodium hydrogen carbonate to a value of 7.0. Fe(III)NTA solution $(2.5 \mu \mathrm{mol} / \mathrm{mouse})$ was given for 6 consecutive days during the first two weeks, followed by a dosage of $5 \mu \mathrm{mol} /$ mouse for 6 consecutive days in the third week (making a total iron loading of $45 \mu \mathrm{mol} / \mathrm{mouse}$ ). Control mice received either normal saline or NTA solution alone. After the last injection, control and treated mice were allowed to rest for 4-5 d before ESR measurement. In iron chelator treated mice, deferoxamine (DF; Ciba Geigy Co., Hyogo, Japan) was i.p. $(0.2 \mu \mathrm{mol} / \mathrm{g}$ body weight) injected $10 \mathrm{~min}$ before Fe(III)-NTA treatment in the last week.

After ESR measurement, mice were sacrificed by exsanguinations from the abdominal aorta following by perfusion with $6-7 \mathrm{~mL}$ of normal saline before removing the liver, kidney and spleen to determine the levels of lipid peroxidation, iron content, GHS and GSH-dependent enzyme activities. All procedures and animal care were approved by the Ethics Committee of Animal Experimentation, Kyushu University, Japan and were conducted according to the Guidelines for Animal Experiments of Kyushu University.

GSH-Depleted Mice GSH-deficient mice were generated by administration of L-buthionine- $[S, R]$-sulfoximine (BSO; Sigma Chemical Co., St. Louis, MO, U.S.A.) as previously described. $^{21,22)}$ For long term treatment, BSO $(2 \mu \mathrm{mol} / \mathrm{g}$ body weight) was i.p. injected to mice twice daily for $7 \mathrm{~d}$. BSO $(10 \mathrm{~mm})$ was also given as drinking water. Control mice were injected with normal saline.

In Vivo ESR Measurement Mice were anaesthetized by intramuscular injection of $\mathrm{Nembutal}^{\circledR}(50 \mathrm{mg} / \mathrm{kg}$ body weight) and fixed onto a Teflon holder. 3-Carbamoyl-2,2,5,5tetramethylpyrrolidine-1-oxyl (Carbamoyl-PROXYL, Aldrich Chem. Co.) $(0.75 \mu \mathrm{mol} / \mathrm{g}$ body weight) was freshly prepared in deionized water and was administrated through the tail vein and ESR spectra were recorded immediately after the injection with an in vivo ESR spectrometer (JEOL, JES-PE-1X) equipped with an L-band microwave power unit (ES-LBIC) and a loop-gap resonator (diameter $33 \mathrm{~mm}$, length $5 \mathrm{~mm}$ and $Q=700$ ), at a microwave frequency of $1.1 \mathrm{GHz}, 1.0 \mathrm{~mW}$ power and amplitude of the $100 \mathrm{kHz}$ field modulation of $0.125 \mathrm{mT}$. The external magnetic field was swept at a scan rate of $5 \mathrm{mT} /$ min. Signal intensity was obtained from ESR signal at the lower magnetic field and the initial rate constant of signal decay $(k)$ was calculated from the slope of a semi-logarithmic plot of signal intensity versus time after injection. The representative of signal decay curves in NTA and Fe(III)-NTA

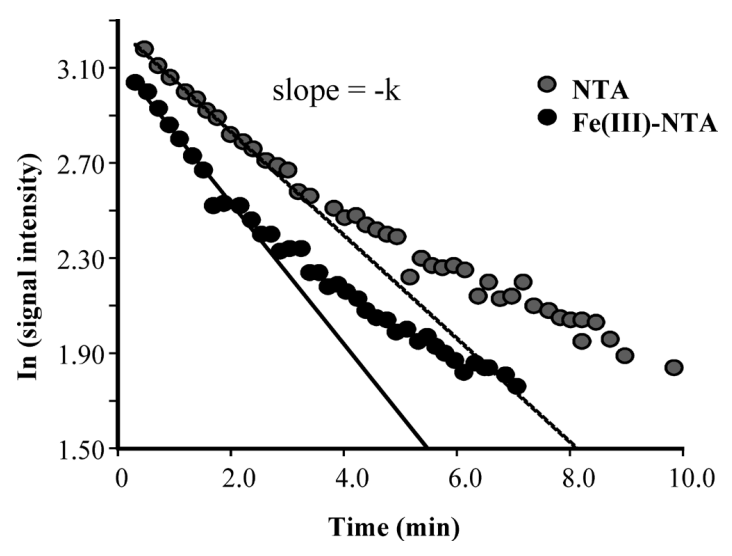

Fig. 1. ESR Signal Decay Curves of Carbamoyl-PROXYL in Upper Abdomen of NTA and Fe(III)-NTA Treated Mice

treated mice are shown in Fig. 1.

Tissue Iron Content Amounts of non-heme iron in liver, kidney and spleen were determined using a modification of the methods of Simpson and Peters ${ }^{23)}$ and Foy et al. ${ }^{24)}$ In brief, tissue samples were homogenized in $10 \mathrm{~mm} \mathrm{NaOH}-\mathrm{N}$ (2-hydroxyethyl)piperazine- $N^{\prime}$-2-ethanesulfonic acid (Hepes) buffer ( $\mathrm{pH} 7.0$ ) containing $0.15 \mathrm{M} \mathrm{NaCl}$ at a ratio of $1: 5(\mathrm{w} / \mathrm{v})$. Non-heme iron was extracted three times by boiling $0.5 \mathrm{~mL}$ of homogenate with $1 \mathrm{~mL}$ of an acid solution of $12.5 \%$ trichloroacetic acid (TCA) containing 2\% sodium phosphate for $15 \mathrm{~min}$. One milliliter aliquot of the solution was mixed with $2 \mathrm{~mL}$ of $1 \mathrm{~mm}$ ferrozine in $50 \mathrm{~mm}$ sodium ascorbate and $1.05 \mathrm{~mm}$ sodium acetate and left at room temperature for $15 \mathrm{~min}$ before measuring absorbance at $562 \mathrm{~nm}$.

Tissue Lipid Peroxidation Concentrations of thiobarbituric acid-reactive substances (TBARs) in liver and kidney were measured spectrometrically using a modified method of Asakawa and Matsushita. ${ }^{25)}$ In short, tissue was homogenized in $1.15 \% \mathrm{KCl}$ containing $5 \mathrm{~mm}$ BHT at a ratio of $1: 10(\mathrm{w} / \mathrm{v})$. A $0.5 \mathrm{~mL}$ aliquot of the homogenate was mixed with $2.2 \%$ TCA, $0.5 \mathrm{~mm}$ ethylenediaminetetraacetic acid (EDTA) and $0.8 \%$ sodium dodecyl sulfate (SDS) (final concentrations) and then incubated with $0.2 \%$ TBA in boiling water for $45 \mathrm{~min}$. After cooling, chromogen was extracted with $n$-butanol and the concentration of TBARs was calculated from the difference between absorption values of the butanol-extracted supernatant at 532 and $520 \mathrm{~nm}$, using 1,1,3,3-tetraethoxypropane as the standard.

Tissue Total Glutathione Total glutathione content was determined using dithio-bis(nitrobenzoic acid) (DTNB)-glutathione reductase recycling method. ${ }^{26)}$ In brief, liver and kidney samples were homogenized in $0.1 \mathrm{M}$ sodium phosphate buffer $(\mathrm{pH} 7.5)$ at a ratio of $1: 5(\mathrm{w} / \mathrm{v})$. The homogenate was mixed with an equal volume of $4 \%$ salicylic acid and centrifuged at $233 \times \boldsymbol{g}$ for $15 \mathrm{~min}$ at $4^{\circ} \mathrm{C}$. The assay mixture $(2.65 \mathrm{~mL})$ contained $25 \mu \mathrm{L}$ of the supernatant or $50 \mu \mathrm{L}$ of standard GSH solution, $0.30 \mathrm{~mm}$ NADPH, $2.4 \mathrm{U}$ GSH reductase (Type III from Barkers yeast; Sigma) and $2 \mathrm{~mL}$ of $10 \mathrm{~mm}$ sodium phosphate buffer containing $0.5 \mathrm{~mm}$ EDTA. After incubating at $30^{\circ} \mathrm{C}$ for $5 \mathrm{~min}$, the sample was mixed with $0.75 \mathrm{~mm}$ DTNB and absorbance was measured at $412 \mathrm{~nm}$ after $1 \mathrm{~min}$. A standard curve was constructed using 25-200 $\mu \mathrm{M} \mathrm{GSH}$.

GSH-Dependent Enzymes Activities Activity of glutathione peroxidase $(\mathrm{GPx})$, glutathione reductase and glutathi- 
one- $S$-transferase activity was assayed according to the method of Yamamoto and Takahashi, ${ }^{27)}$ Carlberg and Mannervik ${ }^{28)}$ and Simons and Vander, ${ }^{29)}$ respectively.

Statistical Analysis Statistical analysis was performed using SPSS software (version 11.5; SPSS, Chicago, Ill, U.S.A.). Data were expressed as mean \pm S.D. unless otherwise indicated. Comparisons of the studied parameters were analyzed by one way analysis of variance (ANOVA) with Tukey test as a post test. Relationships between the studied parameters were evaluated by Spearman rank correlation analysis, with $p$-value $<0.05$ considered significant.

\section{RESULTS}

Characteristics of Oxidative Stress in Iron Overloaded Mice Characteristics of iron overloaded mice induced by i.p. injection of $\mathrm{Fe}(\mathrm{III})-\mathrm{NTA}$ included 4-5 fold increase in iron content of liver, kidney and spleen, hepatomegaly and splenomegaly, and reduced kidney weight (Table 1). Evidences of oxidative stress were shown by reduction in liver GSH and increase in TBARs levels (Table 2). A slightly negative correlation of liver GSH and TBARS were observed $(r=-0.543$, $p<0.001$ ), indicating partial contribution of GSH as an antioxidant in this system. However, activities of GSH-dependent enzymes (glutathione peroxidase, glutathione- $S$-transferase and glutathione reductase) were not altered. Interestingly, GSH level in kidney was increased 2 fold. There are no significant changes in kidney lipid peroxidation or in activities of GSHdependent enzymes.

Treatment of DF at the last week of iron loading slightly reduced iron content in liver, $4.2 \pm 0.3$ and $5.2 \pm 0.3 \mu \mathrm{mol} / \mathrm{g}$ liver with and without DF treatment, respectively. Moreover, DF treatment did not inhibit the formation of liver TBARs (Fig. 2a) nor the decline of liver GSH level in these iron overloaded mice.

ESR Signal Decay of Carbamoyl-PROXYL in Iron Overloaded Mice Rate constant of ESR signal decay $(k)$ of carbamoyl-PROXYL in the upper abdomen was significantly enhanced in iron overloaded mice compared with those treated with NTA alone (Fig. 2b). Treatment with DF only slightly inhibited this enhanced ESR decay. There was a slightly negative correlation between rate of signal decay and liver GSH level (Fig. 3), implying the relationship of oxidative stress and rate of ESR signal decay.

ESR Signal Decay in GSH-Depleted Mice To verify that

Table 1. Characteristics of Iron Overloaded Mice Induced by Ferric Nitrilotriacetate

\begin{tabular}{cccc}
\hline \hline Parameter & Control $(n=15)$ & NTA $(n=15)$ & $\begin{array}{c}\text { Fe(III)-NTA } \\
(n=26)\end{array}$ \\
\hline Body weight $(\mathrm{g})$ & $37.2 \pm 0.6$ & $36.3 \pm 0.8$ & $34.1 \pm 0.5$ \\
Organ weight $(\mathrm{g})$ & & & \\
Liver & $2.0 \pm 0.07$ & $2.0 \pm 0.07$ & $2.2 \pm 0.05^{* *}$ \\
Kidney & $0.6 \pm 0.02$ & $0.6 \pm 0.02$ & $0.5 \pm 0.02$ \\
Spleen & $0.1 \pm 0.01$ & $0.1 \pm 0.01$ & $0.2 \pm 0.01^{* *}$ \\
Iron content $(\mu \mathrm{mol} / \mathrm{g}$ tissue $)$ & & \\
Liver & $1.2 \pm 0.1$ & $1.3 \pm 0.1$ & $5.2 \pm 0.3^{* *}$ \\
Kidney & $0.3 \pm 0.01$ & $0.3 \pm 0.01$ & $1.4 \pm 0.1^{* *}$ \\
Spleen & $1.8 \pm 0.1$ & $2.4 \pm 0.5$ & $8.8 \pm 1.4^{* *}$ \\
\hline Results are presented as mean + S.D. $* * *<0.01$ compared with control.
\end{tabular}

GSH reduces the rate of decay of EPR signal, measurements were conducted in GSH-depleted mice. After $2 \mathrm{~h}$ of a single injection of $2 \mu \mathrm{mol} \mathrm{BSO} / \mathrm{g}$ body weight, liver $\mathrm{GSH}$ content decreased $40 \%$ compared with control. However, twice daily administration of BSO for $4 \mathrm{~d}$ did not cause any further decline of liver GSH level. GSH-depletion by this procedure did not affect rate of EPR signal decay. On the other hand, supplement of BSO in drinking water together with i.p. injections of BSO $2 \mu \mathrm{mol} / \mathrm{g}$ body weight twice daily for 7 consecutive days eliminated almost all of the liver GSH content (Table 3), without affecting liver TBARs level, or serum glutamate oxaloacetate transaminase (GOT), liver GPx and liver GR activities compared with control mice (data not shown). This was accompanied by a significant reduction in rate constant of ESR signal decay $\left(k=0.153 \pm 0.006\right.$ and $0.186 \pm 0.008 \mathrm{~min}^{-1}$ for BSO treated and control group, respectively) (Table 3 ).

\section{DISCUSSION}

In the present study, we demonstrated that measurement of the rate of ESR signal decay with a membrane permeable spin probe, carbamoyl-PROXYL, could provide a sensitive indicator for monitoring free radical production in liver of an intact animal.

Ferrokinetic experiments showed that iron was rapidly cleared from plasma with a concomitant uptake in the liver (data not shown). The maximum amount of liver iron content was reached within $24 \mathrm{~h}$ of i.p. injection of Fe(III)-NTA. Hence, at the time of ESR measurement (4-5d after the last injection), the majority of the injected iron had already accumulated in tissues. We concluded that intracellular iron mainly contributed the enhanced rate of signal decay in iron overloaded mice. ${ }^{15,30,31)} \mathrm{DF}$ is a membrane impermeable iron chelator and it does not effectively chelated iron from intracellular pool. Therefore, the significant effects of DF were not observed in this experiment.

Table 2. Tissue Levels of TBARs, GSH and Activities of GSH-Dependent Enzymes

\begin{tabular}{cccc}
\hline \hline Parameter & Control $(n=15)$ & NTA $(n=15)$ & $\begin{array}{c}\text { Fe(III)-NTA } \\
(n=26)\end{array}$ \\
\hline $\begin{array}{c}\text { Liver } \\
\text { TBARs } \\
\quad(\mathrm{nmol} / \mathrm{g}\end{array}$ & $73.8 \pm 15.2$ & $76.9 \pm 9.4$ & $90.5 \pm 13.2^{*}$ \\
$\quad$ tissue $)$ & & & \\
GSH $(\mu \mathrm{mol} / \mathrm{g}$ & $4.7 \pm 1.7$ & $4.2 \pm 1.4$ & $2.9 \pm 0.8^{*}$ \\
$\quad$ tissue $)$ & & & \\
GPx & $245.9 \pm 11.4$ & $260.4 \pm 6.3$ & $268.2 \pm 8.4$ \\
GR & $69.7 \pm 2.4$ & $65.2 \pm 2.0$ & $77.5 \pm 4.5$ \\
GST & nd & $4.9 \pm 0.3$ & $3.2 \pm 0.2$ \\
Kidney & & & \\
TBARs & $57.4 \pm 3.3$ & $52.7 \pm 2.5$ & $55.2 \pm 5.4$ \\
$\quad(\mathrm{nmol} / \mathrm{g}$ & & & \\
tissue $)$ & & & \\
GSH $(\mu \mathrm{mol} / \mathrm{g}$ & $48.5 \pm 11.1$ & $26.4 \pm 4.5$ & $110.8+23.1 * *$ \\
$\quad$ tissue $)$ & & & \\
GPx & $310.4 \pm 9.4$ & $274.2 \pm 6.3$ & $314.5 \pm 14.0$ \\
GR & $150.4 \pm 6.8$ & $129.3 \pm 5.4$ & $146.4 \pm 17.5$ \\
GST & nd & $532.9 \pm 19.7$ & $487.6 \pm 36.1$ \\
\hline
\end{tabular}

Results are presented as mean \pm S.D.; $* p<0.05, * * p<0.01$ compared with control. Activities of GPx and GR are expressed as nmol NADPH oxidized $/ \mathrm{min} / \mathrm{mg}$ protein. Activity of GST is expressed as nmol CDNB formed/min/mg protein. 


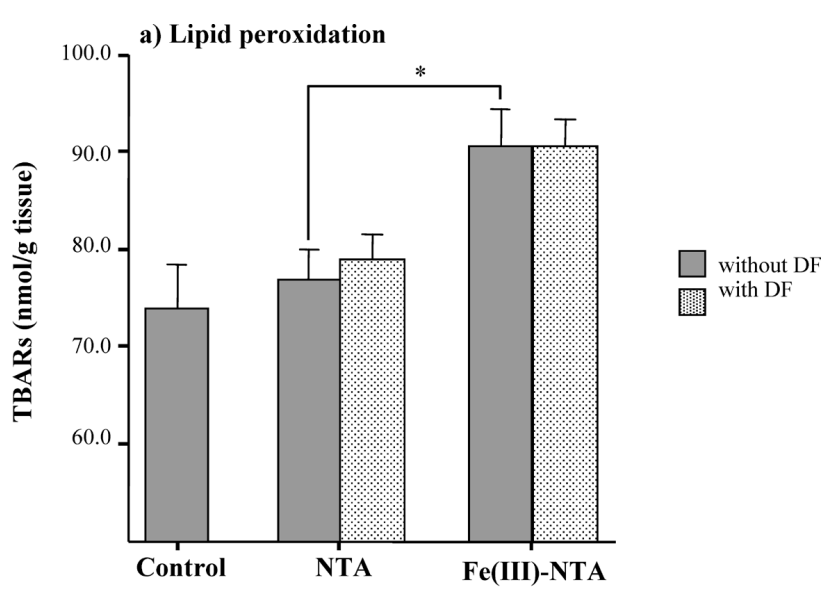

b) Rate constant of signal decay (k)

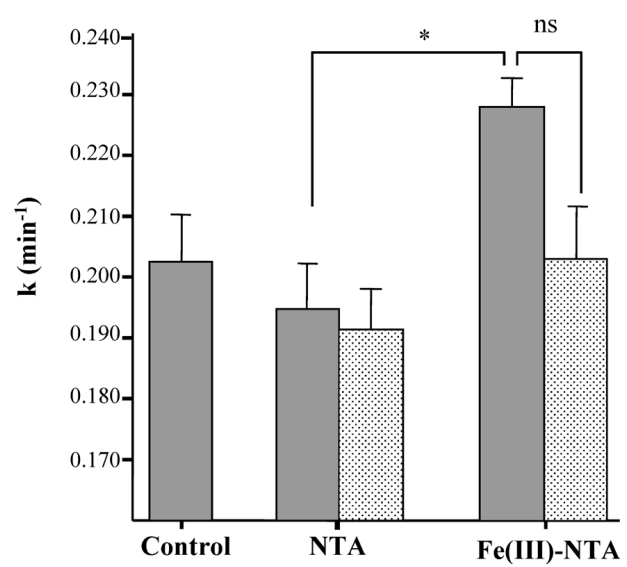

Fig. 2. Effects of Iron Overloading of Mice with Fe(III)-NTA on Liver Lipid Peroxidation (a) and Rate Constant of ESR Signal Decay, $k\left(\mathrm{~min}^{-1}\right)$, of Carbamoyl-PROXYL in Upper Abdomen (b)

Mice were i.p. loaded with Fe(III)-NTA for 3 weeks, total iron content $45 \mu \mathrm{mol} /$ mouse. NTA was i.p. injected into mice in the equivalent molar of NTA in iron overloaded group. DF $(0.2 \mu \mathrm{mol} / \mathrm{g}$ body weight $)$ was i.p. at the last week of iron loading and continued daily during $4-5 \mathrm{~d}$ equilibration period. ESR measurement was performed after equilibration period. $* p<0.05$.

The rate of ESR signal decay of carbamoyl-PROXYL can be affected by hepatic GSH in two different circumstances. $\mathrm{Fe}(\mathrm{III})-\mathrm{NTA}$ itself is a potent liver GSH exhauster, and a reduction in hepatic GSH level causes an accumulation of free radical production and lipid peroxidation. ${ }^{32)}$ We assumed that reduction of hepatic GSH caused by Fe(III)-NTA additively increases free radical production in iron overloaded mice. Thus, the rate of ESR signal decay tended to be increased in

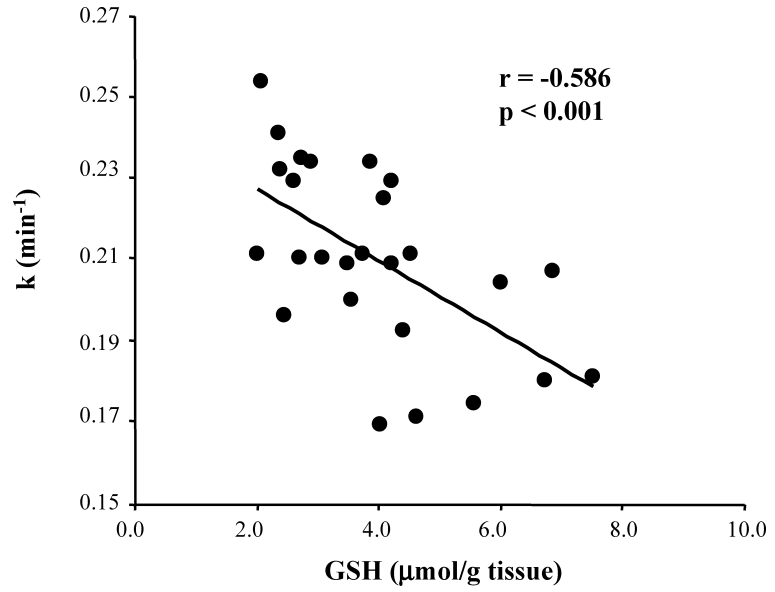

Fig. 3. Correlation between Liver GSH Level Rate Constant of ESR Signal Decay, $k\left(\mathrm{~min}^{-1}\right)$, of Carbamoyl-PROXYL in Upper Abdomen of Iron Overloaded Mice

Mice were i.p. loaded with Fe(III)-NTA for 3 weeks, total iron content $45 \mu \mathrm{mol} /$ mouse. ESR measurement and liver GSH was performed $4-5 \mathrm{~d}$ after the last injection of iron loading.

iron overloaded mice with low levels of hepatic GSH.

On the other hand, reduction of hepatic GSH induced by BSO attenuated the rate of ESR signal decay. BSO is wildly used to induce intracellular GSH depletion both in cell culture and in animal models, by specifically and irreversibly inhibiting $\gamma$-glutamylcysteine synthetase $(\gamma$-GCS), the rate-limiting enzyme of GSH biosynthesis. ${ }^{33)}$ In mice, injection of BSO produces a rapid decrease of GSH levels of liver, kidney and plasma, whereas other tissues are less affected. ${ }^{34)}$ In our study, BSO giving in drinking water together with i.p. injection effectively lowered liver GSH level. In the situation where GSH level was only $20 \%$ of control, there was no evidence of acute toxicity, evaluated using liver TBARs, and serum aspartate aminotransferase (AST), liver GPx and liver GR activities. Thus the retardation of carbamoyl-PROXYL ESR signal decay in this case did not result from hepatic damage but is due to reduction of intracellular GSH level.

Paramagnetic nitroxyl spin probes can be reduced to the diamagnetic hydroxylamine directly or via an intermediate oxoammonium cations in living animal. ${ }^{35)}$ GSH acts as a hydrogen donor in both pathways of nitroxyl reduction. Kuppusamy et al. $^{36)}$ have demonstrated that high concentrations of GSH in tumor tissues accelerate the reduction of carbamoylPROXYL. Treatment of BSO to tumor tissue, on the other hand, delays the reduction rate. Thus, alterations of redox

Table 3. Level of Liver GSH and Rate Constant of ESR Signal Decay of Carbamoyl-PROXYL in BSO Treated and Single Iron Overloading Regimen Treated Mice

\begin{tabular}{|c|c|c|c|c|}
\hline & Liver GSH ( $\mu \mathrm{mol} / \mathrm{g}$ tissue $)$ & $k\left(\min ^{-1}\right)$ & Liver TBARs (nmol/g tissue) & Serum AST (U/L) \\
\hline Control $(n=14)$ & $5.0 \pm 0.2$ & $0.186 \pm 0.029$ & $67.3 \pm 9.6$ & $87.2 \pm 6.1$ \\
\hline Iron overloaded $(n=13)$ & $4.4 \pm 0.2$ & $0.279 \pm 0.032$ & $82.5 \pm 4.8$ & $114.9 \pm 24.9$ \\
\hline \multicolumn{5}{|l|}{ BSO treatment } \\
\hline i.p. 2 h $(n=10)$ & $3.0 \pm 0.3$ & $0.177 \pm 0.018$ & nd & nd \\
\hline i.p. $4 \mathrm{~d}(n=5)$ & $3.7 \pm 0.6$ & $0.170 \pm 0.020$ & nd & nd \\
\hline i.p./oral $7 \mathrm{~d}(n=18)$ & $0.9 \pm 0.2 * *$ & $0.153 \pm 0.025^{* *}$ & $57.6 \pm 3.2$ & $86.7 \pm 11.2$ \\
\hline $\begin{array}{l}\text { i.p./oral } 7 \mathrm{~d}+\text { iron loading } \\
\quad(n=14)\end{array}$ & $0.9 \pm 1.0$ & $0.23 \pm 0.037$ & $76.1 \pm 4.6$ & $112.2 \pm 17.6$ \\
\hline
\end{tabular}

Results are presented as mean \pm S.D.; ${ }^{* *} p<0.01$ compared with control. 
status may influence the reduction of nitroxyl spin probes regardless of free radical production.

It is worth noting that the depletion of GSH by BSO showed neither an additive effect on the enhanced rate of ESR signal decay nor on liver TBARs levels in mice receiving a single iron overloading injection. Martensson and Meister ${ }^{37)}$ reported that ascorbate synthesis is increased in liver of adult mice treated with BSO. Presumably this adaptive response was not sufficient to protect against iron intoxication in case of chronic iron overloading.

It should be noted that although kidney is a target organ for Fe(III)-NTA toxicity ${ }^{38,39)}$ increased lipid peroxidation was not observed in our study. This could have resulted from increased concentration of GSH in the kidney of iron overloaded mice, without alterations in GSH-dependent enzyme activities. This adaptive response could due to an increase in GSH synthesis and uptake. ${ }^{40)}$ However, variations in results of alteration of GSH levels and GSH-dependent enzyme activities have been reported in various iron overloaded models. These discrepancies were probably due to different routes, forms and periods of iron loading as well as adaptive response in different species of animals.

In summary, we have demonstrated that the in situ enhanced ESR signal decay of carbamoyl-PROXYL is related to lipid peroxidation and GSH levels in the upper abdomen of Fe(III)-NTA loaded mice. This method could be applied for monitoring the activity and efficacy of antioxidants and iron chelators. However, the influence of endogenous reducing agents, such as GSH, should be taken into account in the interpretation of free radical production in each specific experimental setting. The interaction of GSH and nitroxyl spin probe in iron overload condition requires further investigations.

Acknowledgments This work was supported by Young Investigator's Grant from Innovation Center for Medical Redox Navigation, Kyushu University to NK, by Grant-in-Aid and Core-to-Core Program for Scientific Research from Japan Society for the Promotion of Science (JSPS), by Japan Science and Technology Agency (JST) and by Research Grant No. RMU 5080058 from the Thailand Research Fund (TRF) and the Commission on Higher Education to NPM. Authors acknowledge Prof. Prapon Wiliarat, Department of Biochemistry, Faculty of Science, Mahidol Univerisity for his kind text editing this manuscript.

\section{REFERENCES}

1) Weatherall DJ, Clegg JB. The thalassaemia syndromes. 4th ed., Backwell Science, Oxford (2001).

2) Toyokuni S. Role of iron in carcinogenesis: cancer as a ferrotoxic disease. Cancer Sci., 100, 9-16 (2009).

3) Utsumi H, Yamada K. In vivo electron spin resonance-computed tomography/nitroxyl probe technique for non-invasive analysis of oxidative injuries. Arch. Biochem. Biophys., 416, 1-8 (2003).

4) Takeshita K, Saito K, Ueda J, Anzai K, Ozawa T. Kinetic study on ESR signal decay of nitroxyl radicals, potent redox probes for in vivo ESR spectroscopy, caused by reactive oxygen species. Biochim. Biophys. Acta, 1573, 156-164 (2002).

5) Goldstein S, Merenyi G, Russo A, Samuni A. The role of oxoammonium cation in the SOD-mimic activity of cyclic nitroxides. $J$. Am. Chem. Soc., 125, 789-795 (2003).

6) Soule BP, Hyodo F, Matsumoto K, Simone NL, Cook JA, Krishna
MC, Mitchell JB. The chemistry and biology of nitroxide compounds. Free Radic. Biol. Med., 42, 1632-1650 (2007).

7) Hyodo F, Soule BP, Matsumoto K, Matusmoto S, Cook JA, Hyodo E, Sowers AL, Krishna MC, Mitchell JB. Assessment of tissue redox status using metabolic responsive contrast agents and magnetic resonance imaging. J. Pharm. Pharmacol., 60, 1049-1060 (2008).

8) Ichikawa K, Sakabe E, Kuninobu K, Yamori T, Tsuruo T, Yao T, Tsuneyoshi M, Utsumi $\mathrm{H}$. Application of in vivo ESR/spin-probe technique to monitor tumor in vivo in mouse footpad. Antioxid. Redox Signal., 9, 1699-1707 (2007).

9) Utsumi H, Yasukawa K, Soeda T, Yamada K, Shigemi R, Yao T, Tsuneyoshi M. Noninvasive mapping of reactive oxygen species by in vivo electron spin resonance spectroscopy in indomethacin-induced gastric ulcers in rats. J. Pharmacol. Exp. Ther., 317, 228-235 (2006).

10) Yamada $K$, Nakamura $T$, Utsumi $H$. Enhanced intraarticular free radical reactions in adjuvant arthritis rats. Free Radic. Res., 40, 455-460 (2006).

11) Lee MC, Shoji H, Miyazaki H, Yoshino F, Hori N, Toyoda M, Ikeda Y, Anzai K, Ikota N, Ozawa T. Assessment of oxidative stress in the spontaneously hypertensive rat brain using electron spin resonance (ESR) imaging and in vivo L-Band ESR. Hypertens. Res., 27, 485-492 (2004).

12) Yamato $M$, Egashira $T$, Utsumi H. Application of in vivo ESR spectroscopy to measurement of cerebrovascular ROS generation in stroke. Free Radic. Biol. Med., 35, 1619-1631 (2003).

13) Han JY, Takeshita K, Utsumi H. Noninvasive detection of hydroxyl radical generation in lung by diesel exhaust particles. Free Radic. Biol. Med., 30, 516-525 (2001).

14) Miura Y, Ozawa T. Noninvasive study of radiation-induced oxidative damage using in vivo electron spin resonance. Free Radic. Biol. Med., 28, 854-859 (2000).

15) Phumala N, Ide T, Utsumi H. Noninvasive evaluation of in vivo free radical reactions catalyzed by iron using in vivo ESR spectroscopy. Free Radic. Biol. Med., 26, 1209-1217 (1999).

16) Hamazaki S, Okada S, Ebina Y, Fujioka M, Midorikawa O. Nephrotoxicity of ferric nitrilotriacetate. An electron-microscopic and metabolic study. Am. J. Pathol., 123, 343-350 (1986).

17) Li JL, Okada S, Hamazaki S, Ebina Y, Midorikawa O. Subacute nephrotoxicity and induction of renal cell carcinoma in mice treated with ferric nitrilotriacetate. Cancer Res., 47, 1867-1869 (1987).

18) Iqbal M, Giri U, Athar M. Ferric nitrilotriacetate (Fe-NTA) is a potent hepatic tumor promoter and acts through the generation of oxidative stress. Biochem. Biophys. Res. Commun., 212, 557-563 (1995).

19) Awai M, Narasaki M, Yamanoi $Y$, Seno S. Induction of diabetes in animals by parenteral administration of ferric nitrilotriacetate. A model of experimental hemochromatosis. Am. J. Pathol., 95, 663-673 (1979).

20) Agarwal MK, Iqbal M, Athar M. Vitamin E inhibits hepatic oxidative stress, toxicity and hyperproliferation in rats treated with the renal carcinogen ferric nitrilotriacetate. Redox Rep., 10, 62-70 (2005).

21) Sun JD, Ragsdale SS, Benson JM, Henderson RF. Effects of the long-term depletion of reduced glutathione in mice administered L-buthionine-S,R-sulfoximine. Fundam. Appl. Toxicol., 5, 913-919 (1985).

22) Watanabe $T$, Sagisaka H, Arakawa S, Shibaya $Y$, Watanabe M, Igarashi I, Tanaka K, Totsuka S, Takasaki W, Manabe S. A novel model of continuous depletion of glutathione in mice treated with L-buthionine( $S, R)$ sulfoximine. J. Toxicol. Sci., 28, 455-469 (2003).

23) Simpson RJ, Peters TJ. Forms of soluble iron in mouse stomach and duodenal lumen: significance for mucosal uptake. Br. J. Nutr., 63, 79-89 (1990).

24) Foy AL, William HL, Cortell S, Conrad ME. A modification procedure for the determination of non-heme iron in tissue. Anal. 
Biochem., 18, 559-563 (1967).

25) Asakawa $T$, Matsushita S. Coloring condition of thiobabituric acid test for detecting lipid peroxide. Lipids, 15, 137-140 (1980).

26) Kondo T, Sawada F. Experimental protocols for reactive oxygen and nitrogen species. (Taniguchi N, Gutteridge JMC eds.), Oxford University Press, London, pp. 57-60 (2000).

27) Yamamoto Y, Takahashi K. Glutathione peroxidase isolated from plasma reduces phospholipid hydroperoxides. Arch. Biochem. Biophys., 305, 541-545 (1993).

28) Carlberg I, Mannervik B. Purification and characterization of the flavoenzyme glutathione reductase from rat liver. J. Biol. Chem., 250, 5475-5480 (1975).

29) Simons PC, Vander Jagt DL. Purification of glutathione $S$-transferases from human liver by glutathione-affinity chromatography. Anal. Biochem., 82, 334-341 (1977).

30) Kakhlon O, Cabantchik ZI. The labile iron pool: characterization, measurement, and participation in cellular processes (1). Free Radic. Biol. Med., 33, 1037-1046 (2002).

31) Zanninelli G, Loréal O, Brissot P, Konijn AM, Slotki IN, Hider RC, Ioav Cabantchik Z. The labile iron pool of hepatocytes in chronic and acute iron overload and chelator-induced iron deprivation. $J$. Hepatol., 36, 39-46 (2002).

32) Iqbal M, Sharma SD, Rezazadeh H, Hasan N, Abdullah M, Athar M. Glutathione metabolizing enzymes and oxidative stress in ferric nitrilotriacetate mediated hepatic injury. Redox Rep., 2, 385-391 (1996).

33) Anderson ME. Glutathione: an overview of biosynthesis and modulation. Chem. Biol. Interact., 111-112, 1-14 (1998).
34) Griffith OW, Meister A. Translocation of intracellular glutathione to membrane-bound gamma-glutamyl transpeptidase as a discrete step in the gamma-glutamyl cycle: glutathionuria after inhibition of transpeptidase. Proc. Natl. Acad. Sci. U.S.A., 76, 268-272 (1979).

35) Krishna MC, Grahame DA, Samuni A, Mitchell JB, Russo A. Oxoammonium cation intermediate in the nitroxide-catalyzed dismutation of superoxide. Proc. Natl. Acad. Sci. U.S.A., 89, 55375541 (1992)

36) Kuppusamy P, Li H, Ilangovan G, Cardounel AJ, Zweier JL, Yamada K, Krishna MC, Mitchell JB. Noninvasive imaging of tumor redox status and its modification by tissue glutathione levels. Cancer Res., 62, 307-312 (2002).

37) Mårtensson J, Meister A. Glutathione deficiency increases hepatic ascorbic acid synthesis in adult mice. Proc. Natl. Acad. Sci. U.S.A., 89, 11566-11568 (1992).

38) Toyokuni S, Uchida K, Okamoto K, Hattori-Nakakuki Y, Hiai H, Stadtman ER. Formation of 4-hydroxy-2-nonenal-modified proteins in the renal proximal tubules of rats treated with a renal carcinogen, ferric nitrilotriacetate. Proc. Natl. Acad. Sci. U.S.A., 91, 2616-2620 (1994).

39) Yamaguchi R, Hirano T, Asami S, Chung MH, Sugita A, Kasai H. Increased 8-hydroxyguanine levels in DNA and its repair activity in rat kidney after administration of a renal carcinogen, ferric nitrilotriacetate. Carcinogenesis, 17, 2419-2422 (1996).

40) Kawabata T, Ogino T, Awai M. Protective effects of glutathione against lipid peroxidation in chronically iron-loaded mice. Biochim. Biophys. Acta, 1004, 89-94 (1989). 